\title{
Serviço Escola de Psicologia e as Políticas de Saúde e de Assistência Social
}

\author{
Maria Aparecida de França Gomes ${ }^{1}$ \\ Programa de Pós graduação em Psicologia, Universidade Federal do Rio Grande do Norte, \\ Natal, RN, Brasil \\ Serviço Integrado de Psicologia da Universidade Potiguar - Laureate International \\ Universities, Natal, RN, Brasil \\ Magda Dimenstein \\ Departamento de Psicologia da Universidade Federal do Rio Grande do Norte, \\ Natal, RN, Brasil
}

\section{Resumo}

O presente artigo tem como objetivo discutir as práticas desenvolvidas nos Serviços Escola de Psicologia (SEP), na perspectiva da formação de psicólogos para as políticas de saúde e assistência social. Participaram desta pesquisa 57 estagiários e 24 egressos de quatro SEP no Rio Grande do Norte (RN). Foi utilizado como instrumento um questionário, aplicado com estudantes que estavam realizando estágio curricular em cada um dos SEP no ano de 2012. Esse mesmo instrumento foi enviado pelo Conselho Regional de Psicologia (CRP-17), através da plataforma Google, para os egressos concluintes em 2010 e 2011. Os resultados apontam para a predominância do modelo de atenção baseado na psicologia clínica tradicional, embora a articulação com as redes de saúde e de assistência social já possa ser timidamente visualizada. Diferentes modalidades de práticas também foram detectadas, para além das psicoterapias e avaliação psicológica. Contudo, os SEP ainda permanecem isolados, seja dos demais cursos que compõem o rol de categorias profissionais que atuam nesse âmbito, seja dos serviços de saúde e de assistência social.

Palavras-chave: Serviço escola de psicologia, ensino da psicologia, política de saúde, política de assistência social.

\section{Psychology University Services, the Health and Social Welfare Policies}

\begin{abstract}
The current study approaches the practices developed by Psychology Universities Services (SEP - Serviços Escola de Psicologia) and used to train psychologists in health and social welfare policy. The experiment comprised 57 interns and 24 graduates from 4 SEP in Rio Grande do Norte State (RN). Participants anonymously answered a survey distributed in loco, among the interns, and virtually, among the egresses. A questionnaire was handed to curricular internship students in each SEP in 2012, and it was sent via google platform to the 2010 and 2011 graduates by the Regional Council of Psychology (CRP-17). Results indicate the prevalence of the care model based on traditional clinical Psychology, although it is possible to see its slight association with health and social assistance networks. Different
\end{abstract}

Endereço para correspondência: Av. Capitão-Mor Gouveia, 2488, A3, Apto. 75, Cidade da Esperança, Natal, RN, Brasil 59070-400. Fone: (84) 98815-5339. E-mail: cidafrance@gmail.com 
types of practices were detected in addition to psychotherapy and psychological assessments. However, the SEP are still isolated, either from the other courses composing the list of professional categories that operate in this scope or from health and social assistance services.

Keywords: Psychology university services, phycologist graduation, health policy, social welfare policy.

\section{Servicio Escuela de Psicología y las Políticas de Salud y Bienestar Social}

\section{Resumen}

En el artículo se discute las prácticas desarrolladas en los servicios escuela de psicología (SEP) con el propósito de formar psicólogos para actuar en las políticas de salud y bienestar social. Participaron de la investigación 57 practicantes y 24 egresos de cuatro SEP en Rio Grande del Norte (RN). Se utilizó como instrumento un cuestionario junto a los estudiantes que se estaban desarrollando prácticas en cada uno de los SEP en 2012. Este instrumento fue enviado a través de la plataforma Google por el Consejo Regional de Psicología (CRP-17) para los graduados de 2010 y 2011. Los resultados apuntan para la predominancia del modelo de atención basado en la psicología clínica tradicional. Sin embargo la articulación con las redes de salud y bienestar social ya pueda ser tímidamente visualizada. Distintas modalidades de prácticas también fueron detectadas además de las psicoterapias y evaluación psicológica. Pero, los SEP aún están aislados, sea de los otros cursos que componen la lista de categorías profesionales que actúan en ese ámbito, sea de los servicios de salud y de bienestar social.

Palabras clave: Servicio escuela de psicologia, educación en psicologia, política de salud, política de bienestar social.

O presente artigo faz parte da tese de doutorado que estamos desenvolvendo, a qual investiga o modelo e as práticas desenvolvidas pelos Serviços-Escola de Psicologia (SEP) das instituições de ensino do Rio Grande do Norte. Selecionamos esse campo por ele, em primeiro lugar, tratar-se de um espaço privilegiado de aprendizagem para o psicólogo em sua inserção no mercado de trabalho. Além disso, percebemos a necessidade de reinvenção dessa instituição para uma ruptura do seu isolamento dos demais cursos que formam profissionais para atuarem nas redes públicas de assistência social e de saúde, bem como da relação informal que mantêm com as redes de cuidado psicossocial.

Diante da escassez de estudos na perspectiva de problematizar o papel dos SEP na operacionalização dos princípios e diretrizes das políticas públicas de saúde e assistência social, empreendemos esta investigação a partir da experiência das autoras na gestão da saúde, no trabalho em estabelecimentos de saúde e como docentes supervisoras de estágio e coordenadora de SEP, visando contribuir com esse debate.

\section{Considerações sobre a Formação em Psicologia para Atuação nas Po- líticas de Saúde e Assistência Social}

Vários aspectos que perpassam a consolidação da profissão do psicólogo têm chamado a atenção de estudiosos, desde a busca por uma identidade profissional até a necessidade de atualização constante imposta pelas demandas da sociedade contemporânea, que vêm produzindo mudanças tanto na formação quanto no exercício profissional. Sabemos que a psicologia incorporada ao neoliberalismo tem contribuído de forma indiscutível com a produção e o fortalecimento dos dispositivos de manutenção, controle e ordenamento social, sendo alvo do interesse do mercado, tal como se pode observar na quantidade crescente de Instituições de Ensino Superior (IES) privadas em operação no país, bem 
como no que vem sendo associado à categoria em termos de descompromisso com as problemáticas sociais produzidas pelas forças sociais hegemônicas.

Atualmente,

a profissão do psicólogo é um território ocupacional regulamentado, institucionalizado e integrado à dinâmica da sociedade por significativa e crescente demanda comercial [grifos nossos] em quase todos os campos de atividade em que as pessoas atuam, como sujeito e como objeto [grifos nossos] de atenção e de estudo. (Malvezzi, 2010, p. 18).

Houve um crescimento da profissão e das instituições formadoras, após a década de 1970, gerando questionamentos acerca da qualidade da formação. Nesses cinquenta anos de profissão, a sociedade brasileira tem sido marcada por mudanças econômicas, sociais e políticas, demandando reposicionamentos de profissionais de todas as áreas e em especial do psicólogo, sobretudo no que se refere à ampliação de seu campo de atuação, ao estabelecimento e à criação de novas tecnologias, de novas formas de intervir e de conceber os modos de produção de subjetividade.

Algumas práticas descontextualizadas e descomprometidas com as necessidades sociais demandadas pela população brasileira são atribuídas à formação em psicologia, práticas baseadas em concepções a-históricas e abstratas, sem vinculação com o social (Abbad \& Mourão, 2010; Bernardes, 2007; Dimenstein, 1998; Dimenstein \& Macedo, 2010; Lo Bianco, Bastos, Nunes, \& Silva, 1994; Macedo \& Dimenstein, 2011; Spink, 2003; Yamamoto, 2007). Tal formação tem sido o celeiro de profissionais malformados intelectual e profissionalmente, segundo Mello e Patto (2008), que operam, muitas vezes, de forma bastante violenta.

Nesse sentido, questionamo-nos: quais desafios se apresentam atualmente para a psicologia? Consideramos que a educação tem "efeitos de longa duração e que não muda facilmente" (Maturana, 2005, p. 29) e que as práticas educativas interferem nos modos de vida e trabalho. Dessa forma, indagamo-nos: que compromissos a psicologia tem assumido? Que tendências estão se definindo com mais força na realidade dos cursos de formação?

Reconhece-se o engajamento dos psicólogos nos movimentos de transformação da sociedade brasileira, mais especificamente na Reforma Sanitária, na Reforma Psiquiátrica e na Luta Antimanicomial, e a participação ativa nas Conferências Nacionais de Saúde, mais expressamente a partir da década de 1980 (Yamamoto, 2007), eventos que, segundo Bernardes (2010, p. 106), "tiveram efeitos tímidos na formação do(a) psicólogo(a)". Contudo, observamos, mesmo que timidamente, a construção de um "novo lugar social para a psicologia e da sua presença no campo das políticas públicas e práticas sociais" (Dimenstein \& Macedo, 2012, p. 237), que clama por uma formação qualitativamente diferente.

Ademais, concordamos com Ceccim e Feuerwerker (2004) quando denunciam que a formação dos profissionais de saúde - e aqui acrescentamos da assistência social - ainda se encontra dissociada do debate sobre as questões do cuidado e do controle social. Ainda predomina, na psicologia, uma formação organicista. $\mathrm{Na}$ assistência social, há uma grande preocupação em fugir das bases filantrópicas que deram origem à profissão, predominando um certo legalismo nas práticas. O controle social ainda é um tema pouco debatido na formação acadêmica em saúde.

Como sair do lugar comum e confortável da prática individualizante, a-histórica e descontextualizada? Como romper com as concepções etnocêntricas, universalistas e naturalistas de natureza humana e como desmistificar a pretensa neutralidade científica que se busca na construção do conhecimento? Como trabalhar com as demandas dos direitos à saúde integral e dos direitos humanos sem cair na dicotomia indivíduo/ social?

Se há pelo menos vinte anos essas demandas passaram a povoar o universo "psi" brasileiro, perguntamo-nos se a formação tem se configurado como um espaço de oferta de respostas a tamanhos desafios. O sistema educacional universitário, através de seus agentes, tem 
acompanhado a nova configuração profissional demandada pelo próprio Estado? Mais especificamente, os Serviços-Escola têm suas práticas atualizadas para serem inseridos nas redes de assistência social e de saúde?

\section{Os Serviços Escola de Psicologia e sua Atuação nas Políticas Públicas de Assistência Social e de Saúde}

Os estudos acerca dos SEP foram evidenciados a partir de 1983 e surgiram principalmente questionando sua efetividade, eficiência e eficácia, pressupondo um futuro pessimista para esses estabelecimentos (Silvares, 1996). Contudo, há um quantitativo de estudos que apresentam as práticas desenvolvidas nesses estabelecimentos, tendo como foco temas relacionados à psicologia clínica, como observado nos Anais do XII Simpósio de Pesquisa e Intercâmbio Científico da Associação Nacional de Pesquisa e Pós-graduação em Psicologia (ANPEPP), realizado em 2008, em Natal-RN (Silvares, 2008).

Os SEP foram constituídos a partir de uma obrigação legal de existir enquanto lugar de práticas profissionalizantes para o futuro psicólogo, e não de uma necessidade da população por demandar serviços psicológicos (Boeckel et al., 2010; Melo-Silva, Santos, \& Simon, 2005; Nunes, Campezatto, Cruxên, \& Savalhia, 2006). Foram considerados imprescindíveis para o funcionamento dos cursos de psicologia, desde o reconhecimento da profissão no Brasil, em 1962. Desde então, têm como objetivo configurarem-se como locais de exercício de práticas profissionalizantes. Foram contemplados pela Lei n. 4.119/62, que instituía que cada curso de psicologia deveria disponibilizar “. . . serviços clínicos e de aplicação à educação e ao trabalho . .." (1962). A citada lei legitimava o fazer psicológico, distribuído em três áreas principais, a saber: clínica, organizacional e educacional. Consolidava, dessa forma, o espaço de formação enquanto fazer clínico e transportava esse modelo às duas outras áreas: educacional e organizacional.

Mais recentemente, a Resolução n. 8, de 7 de maio de 2004, instituiu as Diretrizes Curricu- lares para os cursos de graduação em psicologia, a qual também preconiza em seu Art. 25 a instalação de um Serviço de Psicologia para atender "às exigências para a formação do psicólogo, congruente com as competências que o curso objetiva desenvolver no aluno e a demandas de serviço psicológico da comunidade na qual está inserido" (Conselho Nacional de Educação, Câmara de Educação Superior, 2004).

Observamos que as duas normatizações, mesmo com a mudança de nomenclatura de Clínica Escola para Serviço Escola, consideram um local de práticas, em que a primeira formulação deixa clara a sobreposição da clínica e a segunda, apesar do avanço, não aponta para práticas interdisciplinares e/ou para um Serviço de Psicologia integrado às redes organizadas pelas políticas sociais. Dessa maneira, "serviço psicológico da comunidade na qual está inserido" deixa o local de práticas indefinido, ainda com resquícios do atendimento psicológico baseado no modelo liberal privatista.

Considerando a legislação e mormente tantos estudos realizados realçando os atendimentos individuais desconectados das políticas sociais, não podemos deixar de considerar a existência de algumas poucas publicações questionando esse modelo. Uma delas é sobre o Serviço de Atendimento Psicológico (SAP) da Faculdade de Psicologia da Pontifícia Universidade Católica do Rio Grande do Sul (PUCRS), que, em 2005, "possibilitava o exercício de atividades de prevenção primária na comunidade e do contato direto com grupos em seu contexto" (Boeckel et al., 2010, p. 43).

Como afirma Bernardes (2007), mesmo que a discussão sobre a formação de psicólogos para a atuação em políticas sociais tenha sido deflagrada desde a década de 1980, em particular para a política de saúde, os SEP têm ainda formado psicólogos para atuar como profissionais liberais. Esse período coincide com um crescimento importante da categoria e das agências formadoras, bem como de expansão das áreas e locais de atuação (Bastos \& Gomide, 1989; Bastos \& Gondim, 2010; Conselho Federal de Psicologia [CFP], 1988, 1992, 1994; Dimenstein, 1998, 2000; Yamamoto 2001, 2012; Yama- 
moto \& Oliveira, 2011; Yamamoto, Siqueira, \& Oliveira, 1997). Ao longo de mais de 20 anos, a categoria foi assumindo algumas características, também ressaltadas pelos pesquisadores já citados: tendência ao assalariamento, precarização e deterioração da remuneração, concentração de $40 \%$ dos profissionais no setor público, ligados às políticas sociais, e de $27,9 \%$ no setor saúde. Contudo, evidenciaram também que nas instituições públicas os psicólogos realizam prioritariamente a aplicação de testes e o psicodiagnóstico (Yamamoto, 2012).

Os dados acima são preocupantes, principalmente considerando que a maioria dos profissionais vinculados ao setor público está inserida em algum componente do Sistema Único de Saúde (SUS) e/ou Sistema Único de Assistência Social (SUAS). Ademais, as atividades relacionadas à avaliação psicológica com a aplicação de testes revelam o que Bernardes e Menengon (2007) já apontaram: o perfil do psicólogo brasileiro tem características advindas da sua própria história, pois, "desde seus primórdios no Brasil, a Psicologia possui vozes hegemônicas produtoras de um tipo de formação sempre vinculada a uma Psicologia Aplicada, originária da Psicologia brasileira" (Bernardes \& Menengon, 2007, p. 14).

Com a institucionalização do SUS, a partir do reordenamento da política nacional de saúde em 1988 e do SUAS em 2005, críticas foram dirigidas a essas vozes hegemônicas presentes na formação do psicólogo, bem como às práticas psicológicas, indicando a necessidade de redefinição do perfil profissional fortemente marcado pelo ideário liberal-privatista-biomédico. Tanto o SUS quanto o SUAS compartilham dos mesmos princípios e diretrizes, buscando assegurar à população níveis de seguridade social, seja a partir de ações de promoção da saúde, tratamento e reabilitação, seja com ações que garantam e promovam direitos sociais, a partir da prevenção e proteção dos chamados riscos sociais (Menicucci, 2002).

Para tanto, essas políticas demandam um novo trabalhador, com mais habilidades e competências para desenvolver recursos assistenciais adequados à população usuária, culturalmente sensíveis e eficazes. Entretanto, observa-se, tal como indicado por Yamamoto (2012) e corroborado por outros autores (Bardagi, Bizarro, Andrade, Audibert, \& Lassanc, 2008; Dimenstein, 1998; Dimenstein \& Macedo, 2012; Noronha, 2003; Paulin \& Luzio, 2009; Pazeto, 2005; Yamamoto et al., 2003), que o perfil clássico parece ter sofrido poucas alterações ao longo dos anos e que ainda se pode encontrar o psicólogo que atua com imagens espelhadas do modelo médico de atendimento, "com um trabalho individualizado, ancorado em relações verticalizadas e não focadas no usuário, por intervenções pouco variadas, circunscritas a queixas e voltadas para a remissão de sintomas" (Dimenstein \& Macedo, 2012, p. 237).

Diante desse quadro, questionamo-nos: qual tem sido o papel dos SEP no processo de formação e de que maneira têm operado na conformação das práticas profissionais, especialmente dessa gama de psicólogos que passa a fazer parte das equipes técnicas vinculadas ao SUS e SUAS? No contexto da graduação, os SEP sempre ocuparam lugar de destaque, uma vez que são espaços obrigatórios requeridos para o funcionamento dos cursos de psicologia. Representam o campo de práticas privilegiado desses cursos e, até pouco tempo, o único. Porém, há críticas importantes acerca desse recurso acadêmico, quanto aos seus limites em termos de capacitação do psicólogo em relação à atuação em diferentes contextos, por exemplo, nas políticas de saúde e assistência social. Há críticas em relação ao próprio recurso, do ponto de vista pedagógico (modelo) e do seu alcance, conforme registrado por Melo-Silva et al. (2005).

Em função desse cenário, realizamos esta pesquisa com o objetivo de conhecer o funcionamento dos SEP das Instituições de Ensino Superior de psicologia do município de Natal. Este estudo foi desenvolvido em quatro Serviços-Escola dos cursos de psicologia de Instituições de Ensino Superior (IES) do Rio Grande do Norte, junto aos docentes, estagiários e egressos. Este artigo objetiva apresentar os resultados referentes à caracterização desses SEP no que diz respeito às modalidades de práticas desenvolvidas e seus efeitos sobre a atuação 
profissional nas políticas sociais, segundo a avaliação de estagiários e egressos.

\section{Método}

Este estudo faz parte de uma pesquisa mais ampla de cunho qualitativo, do tipo observacional-interventivo, realizada com gestores dos cursos, supervisores acadêmicos, técnicos de nível superior, estagiários e egressos dos quatro SEP do município de Natal/RN. O critério de inclusão desses participantes levou em conta o tempo de permanência no Serviço Escola, uma vez que deveriam estar atuando ou terem atuado (egressos) no mínimo por seis meses.

Este artigo visa apresentar especificamente os resultados da etapa realizada com estagiários e egressos dos cursos e da pesquisa documental (sites e folders) sobre as características dos SEP.

Utilizamos como ferramenta de coleta de informações um questionário anônimo, aplicado presencialmente junto aos estagiários e virtualmente com egressos referentes aos anos $2010 \mathrm{e}$ 2011. No caso dos primeiros, os questionários foram entregues em um envelope na recepção de cada SEP durante o segundo semestre do ano letivo de 2012, sendo recolhidos após um período de aproximadamente dois meses. Quanto aos egressos, disponibilizamos um questionário online, o qual foi encaminhado via Conselho Regional de Psicologia 17 aos inscritos nesse Conselho durante o ano de 2011 (egressos de 2010 e 2011).

Tal questionário versava sobre os seguintes aspectos: atividades ofertadas pelo SEP; atividades desenvolvidas pelo estagiário/egresso; relação entre os conteúdos relativos à formação do psicólogo vistos na graduação e as práticas desenvolvidas no Serviço Escola; relação do SEP com as políticas de saúde e assistência social; grau de satisfação com o funcionamento do SEP e contribuição para a formação profissional; sugestão(ões) para (r)estruturação e funcionamento do SEP.

O questionário presencial acompanhava um Termo de Consentimento Livre e Esclarecido (TCLE), informando sobre a pesquisa, o qual foi aceito por todas as instituições envolvidas. Já o questionário online apresentava um TCLE automático para a resposta, aprovado pelo CRP 17, ou seja, caso o psicólogo (egresso) respondesse ao questionário, automaticamente ele estava formalizando o seu consentimento quanto ao uso das informações para os fins da pesquisa.

Foram respondidos 24 questionários pelos egressos de 2010 e 2011 e 57 pelos estagiários de 2012 de três dos quatro SEP. Em um dos SEP, nenhum estagiário respondeu ao questionário, bem como nenhum egresso dessa mesma instituição respondeu ao questionário enviado pelo Conselho Regional de Psicologia.

\section{Resultados e Discussão}

\section{Organização e Funcionamento dos Serviços Escola de Psicologia}

Os SEP das IES do Rio Grande do Norte estão diretamente vinculados aos cursos de psicologia das instituições de ensino, com exceção de um que não tem vínculo direto com o curso, estando subordinado e vinculado diretamente a um centro administrativo de cursos diversos, mantendo certa autonomia em relação à coordenação do curso. Vale salientar que esse Serviço Escola foi o primeiro do $\mathrm{RN}$, tendo sido criado mesmo antes da instalação do primeiro curso de psicologia do RN, em 1965 (Mendes, n.d.).

$\mathrm{Na}$ apresentação dos resultados, cada SEP será denominado de SEP 1, SEP 2, SEP 3 e SEP 4. No que se refere ao espaço físico, todos possuem recepção, inclusive o SEP 3 e o SEP 4 dispõem de recepcionistas exclusivos para o curso de psicologia. No SEP 1 e no SEP 2, há uma recepção para alunos da psicologia e de outros cursos da instituição que vêm procurar atendimento, sendo este oferecido no mesmo espaço. No tocante a esses cursos, há uma recepção compartilhada entre serviço social e direito (SEP 1) e outra entre enfermagem, fisioterapia e nutrição (SEP 2). Cada um desses SEP possui salas para coordenação, atendimento individual, ludoterapia, atividades grupais, sala para estagiários e para supervisão. Em dois SEP, existem salas destinadas aos atendimentos da área organiza- 
cional (consultorias etc.), já no outro serviço, além dos espaços mencionados, há duas salas para atividades grupais, salas de observação com espelho e serviço de áudio que servem às atividades grupais e ludoterapia, sala exclusiva para convivência de estagiários e sala para um núcleo de psicologia social e comunitária.

Quanto ao horário de funcionamento, dois SEP funcionam nos três turnos (manhã, tarde e noite) e dois em dois turnos (manhã e tarde). A clientela atendida é variada, com predominância da população com renda familiar baixa, de até um salário mínimo. As equipes são compostas, na maioria, por psicólogos formados que atuam como técnicos supervisores de campo e docentes supervisores acadêmicos, havendo exceção de um serviço em que a supervisora de campo é também coordenadora do Serviço Escola (SEP 2), do qual não temos estagiários participantes da pesquisa.

Os estagiários dos outros três SEP recebem dois tipos de supervisão, a de campo e a acadêmica. A supervisão de campo é realizada por um profissional psicólogo, contratado pela IES especialmente para acompanhar os estagiários nas atividades dos Serviços-Escola, permanecendo à disposição dos estagiários no cotidiano dos Serviços-Escola para esclarecimento de condutas realizadas nos acolhimentos, plantões e triagens dos Serviços. Além disso, os supervisores de campo auxiliam na preparação de documentos psicológicos, quando necessário, para o estabelecimento de contato formal com outras instituições, realizando, assim, orientações técnicas na prática diária dos Serviços. Já a supervisão acadêmica é realizada por docentes dos cursos, semanalmente e em grupos de estagiários. Esse tipo de supervisão por parte do professor supervisor compreende a escuta do relato das práticas desenvolvidas pelos estagiários e a orientação teórica, técnica e ética para o desenvolvimento do estágio, já que na supervisão acadêmica cada estagiário relata sua prática, enquanto o supervisor orienta a reflexão e avalia a prática. Conforme Oliveira et al. (2014, p. 2), a supervisão realizada nos Serviços-Escola de Psicologia "é um dos importantes pilares que sustentam o campo de formação".
Dos Serviços-Escola pesquisados, somente os dois que possuem mais estagiários contam com as duas modalidades de supervisão, a de campo e a acadêmica. Com relação a esse aspecto, o que nos chama a atenção é que o Serviço Escola com a menor quantidade de estagiários é o que possui o maior contingente de psicólogos contratados, mas estes não realizam a supervisão de campo, somente os atendimentos à população.

Cada SEP pesquisado tem uma maneira diferente de registrar suas diretrizes, por exemplo: o SEP 1 disponibilizou um folder, o SEP 2 e o SEP 3 indicaram o site da IES e o SEP 4 citou o regulamento do Serviço Escola. Considerando essa realidade, pode-se afirmar que o que existe em comum nesses documentos é a disponibilização do serviço para os estudantes do curso de psicologia realizarem suas práticas, com ênfases na saúde e na clínica. As diretrizes (princípios e conceitos especiais) para a caracterização de cada SEP não são claras, contudo cada serviço apresenta um rol de atividades/serviços a serem oferecidos à comunidade interna e externa às IES às quais estão vinculados.

O SEP consta nos projetos pedagógicos dos cursos de psicologia pesquisados, atendendo à legislação, mais especificamente às Diretrizes Nacionais para os Cursos de Psicologia (Ministério da Educação, 2011), como já mencionado. Nos documentos estudados de cada SEP, não ficam evidentes nem o seu alinhamento político-pedagógico nem as suas diretrizes, na medida em que se elenca um rol de atividades desenvolvidas nas quais o atendimento individual é comum a todos. Em um deles (SEP 3), a psicanálise é referenciada como uma das principais linhas de atuação.

Alguns SEP estão funcionando em espaços comuns a outros cursos, mas não apresentam trabalho integrado e sistematizado, como linha de trabalho ou diretriz. As práticas desenvolvidas são instrumentais e a formação também ocorre dessa maneira, a partir de abordagens teóricas que servem ao trabalho psicológico tradicional da psicoterapia, não havendo introdução de diferentes saberes para as demandas, como, por exemplo, do campo da saúde coletiva. Um dos motivos para esse quadro pode estar relacionado 
com a possível falta de inclusão dos SEP nas redes assistenciais das políticas públicas.

As condições físicas dos SEP, em geral, são boas, contudo o modo de funcionamento não favorece a utilização dos espaços de forma integrada aos outros cursos, especificamente no caso dos dois serviços em que há compartilhamento de espaço. Os dois SEP que dispõem de espaço próprio, separado de outros cursos, também possuem espaço físico que poderia ser compartilhado na perspectiva de integração de saberes e práticas.

Os estagiários e egressos vinculam-se ao SEP por meio das diversas modalidades de estágio (obrigatório profissionalizante e não obrigatório) e de pesquisa, bem como através das atividades de extensão e práticas de outras disciplinas curriculares. A maioria iniciou suas atividades no último ano do curso, quando da realização do estágio profissionalizante. Em relação às atividades de pesquisa, verifica-se uma quantidade pouco expressiva das que são realizadas pelos estagiários e egressos.

Os SEP são considerados, nos documentos institucionais de seus respectivos cursos, espaços de realização de extensão universitária que ofertam atividades de assistência ao público interno e externo às IES. Entretanto, poucos estagiários responderam que fazem extensão universitária nesses espaços como parte de seus estágios profissionalizantes. Nesse sentido, apenas 17,5\% dos estagiários e $12,5 \%$ dos egressos pesquisados consideram que estabeleceram vínculos com o SEP da instituição da qual fazem parte, através de projetos de extensão.

A prática da realização de pesquisas nos espaços dos SEP tem sido recomendada (Marturano, Silvares, \& Oliveira, 2014; Romaro \& Capitão, 2003; Silvares, 2006). Essa modalidade da formação faz parte do tripé da educação superior, juntamente com o ensino e a extensão. Contudo, no Rio Grande do Norte, a pesquisa não tem sido contemplada de forma ativa, posto que apenas $13,5 \%$ do total de estagiários e 4,1\% dos egressos entrevistados afirmaram realizar ou ter realizado pesquisa no SEP, considerando que apenas em um deles a pesquisa foi mencionada como forma de vinculação do estagiário ao serviço.
De acordo com quase a totalidade dos estagiários e egressos, $\mathrm{o}$ atendimento psicológico individual é a principal atividade desenvolvida em diversas modalidades, tais como acolhimento, triagem, aconselhamento psicológico e psicoterapia. Há serviços que ampliam suas atividades proporcionando ao estudante o deslocamento a equipamentos sociais da comunidade como escolas, Centro de Referência de Assistência Social (CRAS), Centro de Referência Especializado de Assistência Social (CREAS), unidades de saúde, dentre outros equipamentos disponibilizados às IES através de convênios. Contudo, a realização dos estágios obrigatórios, em três das IES, ocorre, em sua maioria, no próprio serviço vinculado à IES, uma vez que as atividades ofertadas à população são desenvolvidas eminentemente pelos estagiários. Em apenas uma instituição dentre as quatro pesquisadas, as atividades do SEP são realizadas pelos técnicos, além dos próprios estudantes do curso, com o agravante de que nesse serviço não há qualquer interação entre os estagiários e o corpo técnico. Essa distância entre os psicólogos contratados pela IES e os estagiários não auxilia a formação em psicologia, posto que não há transmissão nem contribuição desses profissionais quanto ao ensino, à pesquisa e às atividades de extensão realizadas pelos estagiários.

Boeckel et al. (2010) apontam que, além das atividades clínicas comuns a muitos SEP, existem outros que desenvolvem práticas balizadas na Psicologia Social Comunitária, Psicologia da Saúde, Saúde Coletiva, Psicologia Escolar, Psicologia das Organizações e do Trabalho, dentre outras modalidades. Nos SEP do Rio Grande do Norte, observamos a predominância da clínica e uma tímida realização de atividades nos demais campos/áreas da psicologia. O serviço que apresentou uma maior diversidade de práticas, para além da clínica, é o que conta com a maior quantidade de estagiários. Esse fato sugere que a demanda por locais de estágio nas variadas áreas e a concorrência desses locais entre os cursos de psicologia das quatro IES podem estar impondo que o referido SEP amplie seu leque de atuação e de oferta de práticas devido à carência de campos externos à IES.

Constatamos, portanto, que o modelo de atendimento sob as modalidades de psicoterapia 
individual e avaliação psicológica ou psicodiagnóstico predomina nos SEP do Rio Grande do Norte, havendo uma priorização em relação à área clínica, o que não é uma novidade, considerando o perfil das áreas de atuação do psicólogo brasileiro, com o domínio da área clínica sobre as demais. Além disso, percebe-se ainda um modelo que privilegia as atividades clínicas individuais na formação em psicologia, o que, por sua vez, tem repercussões na identidade profissional do psicólogo, restringindo as possibilidades de inserção em contextos diversos (Gondim, Bastos, \& Peixoto, 2010).

As poucas atividades grupais registradas na pesquisa seguem o paradigma do atendimento individual, com concentração nas psicoterapias. Vale salientar que as modalidades de oficinas, rodas de conversa e reuniões de equipe para discussão dos desdobramentos das demandas que chegam ao SEP passaram a ser executadas regularmente pelo SEP 4 e, esporadicamente, pelo SEP 1. Essas atividades podem representar o início de alguma mudança na formação, mas ainda longe de alcançar a primazia que as práticas tradicionais ocupam.

A predominância das atividades inerentes à psicologia clínica nesses espaços de formação nos impele a questionar sobre o papel norteador das Diretrizes Curriculares Nacionais para os Cursos de Psicologia e, sobretudo, a influência destas nas práticas dos psicólogos nas políticas sociais, principalmente de saúde e assistência social, que têm se apresentado como espaços de crescente ocupação do psicólogo brasileiro, conforme apontam Gondim et al. (2010). Urge a necessidade de esses contribuírem para o desenvolvimento de competências compatíveis que preparem o estudante para atuação nos contextos dessas políticas.

\section{Articulação dos Serviços-Escola com as Redes de Assistência Social e de Saúde}

Os resultados sobre a articulação do SEP com as redes de saúde e assistência social não surpreendem. Tanto pela observação direta quanto pelas respostas dos estagiários e egressos, registramos que o modo de articulação entre os
SEP e os equipamentos das redes do SUAS e do SUS, apesar de existir, ainda é frágil e informal, na medida em que parte dos encaminhamentos é realizada de forma verbal e, quando escritos, muitos não esclarecem os motivos da solicitação do serviço. Observamos que a forma de articulação se estabelece, primordialmente, através do modelo de encaminhamentos provindos do SUS - de profissionais das Unidades Básicas e Especializadas de Saúde: ESF, Clínicas de especialidades, Centros de Atenção Psicossocial (CAPS), hospitais, entre outros; e do SUAS - dos CRAS, dos CREAS, da Casa da Família, de Casas de Passagem e de Conselhos Tutelares da Criança e do Adolescente.

Por sua vez, os SEP do RN recebem as demandas dos citados equipamentos de saúde e de assistência social, realizando, sobretudo, atendimentos individuais sob a modalidade de psicoterapias. Há o registro de algumas experiências com capacitação de Conselheiros Tutelares, grupos de mulheres, grupos de portadores de transtornos mentais graves e suas famílias, grupos com crianças e seus responsáveis, grupos realizados com os educadores das Casas de Passagem de crianças e adolescentes, dentre outras experiências, as quais não correspondem às modalidades de atividades que, em quantidade, se sobreponham às psicoterapias e aos aconselhamentos psicológicos.

A formação nos SEP do RN, por ter a atividade clínica individual como carro-chefe, pode influenciar práticas desenvolvidas no SUS e SUAS. Em pesquisa realizada, Oliveira, Solon, Amorim e Dantas (2011) registraram a existência da atividade clínica como prioritária, em uma quantidade significativa de CRAS, na região metropolitana de Natal, mesmo sem ser prevista pelo SUAS, principalmente nesse tipo de equipamento. Ainda segundo esses pesquisadores, dos 18 psicólogos trabalhadores nos CRAS, 16 realizam psicoterapias, testes, ludoterapia, entre outras modalidades de atendimento psicológico clínico.

No quesito articulação dos SEP com as redes de saúde e assistência social, a maioria dos estagiários (36) respondeu que há articulação, 17 que não há e 4 não assinalaram qualquer das 
duas alternativas. Quanto aos egressos, a questão foi se alguma prática de estágio desenvolvida no Serviço/Clínica Escola era compatível com as práticas desenvolvidas nas redes públicas de saúde e/ou de assistência social. Do total, 12 responderam afirmativamente, 7 que não, 1 que não havia práticas compatíveis com a área da assistência social e 5 não responderam.

Quando indagados sobre as modalidades dessa articulação, suas respostas remetem-se, na maioria, à modalidade de encaminhamento entre os serviços, das redes para os SEP, ou vice-versa. Os referidos encaminhamentos são primordialmente para psicoterapias e avaliação psicológica. Outras modalidades de articulação, apontadas por uma minoria de estagiários e egressos (quantitativo entre parênteses, abaixo), foram as discussões, reuniões e qualificações realizadas com os Conselhos Tutelares das quatro zonas administrativas da cidade, principalmente relacionadas ao atendimento psicológico a vítimas de abuso sexual, encaminhadas por esses órgãos (10 menções); os trabalhos realizados pelos estagiários em Casas de Passagem de crianças e adolescentes (6 menções); o acompanhamento terapêutico (2 menções); e o matriciamento em saúde mental, esse último relatado por apenas um participante da pesquisa.

Os CRAS e o CREAS realizam encaminhamentos para os serviços. Geralmente, as pessoas são encaminhadas formalmente pelo psicólogo/a ou outro profissional dos Centros para acompanhamento (psicoterapia, ludoterapia) e/ou avaliação psicológica. No que se refere à formação através dos SEP para atuação na política social pública de assistência social, a pesquisa ratifica o que Oliveira et al. (2011) asseveram sobre o trabalho dos psicólogos nessa política: “. . . Assim, o campo da Assistência Social possibilita aos psicólogos atuar nos serviços de combate à pobreza, mas os desafios da própria política social e os entraves que acompanham a história da profissão permanecem" (p. 140).

Do exposto, podemos identificar que a articulação entre o SEP e as redes assistenciais do SUS e SUAS ainda carece de formalização. No que se refere à articulação, há carência da responsabilização compartilhada entre os dois entes, tendo em vista que muitas vezes se realiza apenas um atendimento, o qual se resume a um encaminhamento, culminando no repasse de problemas, pois, em geral, quem encaminha se desresponsabiliza do caso, da situação, sem utilizar instrumentos adequados que possibilitem a efetivação da contrarreferência. Quem encaminha não sabe dos desdobramentos do caso, nem busca saber; quem recebe, não costuma fornecer informação sobre o atendimento.

No que concerne à formalização dos SEP nas políticas públicas de saúde e assistência social, identificamos que não há reconhecimento oficial dos SEP como dispositivos das políticas. Dessa forma, a relação entre eles é oficiosa. A inclusão formal dos SEP nas redes de assistência pressupõe uma relação formal entre os órgãos executores das políticas de saúde e de assistência social (secretarias municipais); que o desenho de rede de cada órgão poderia incluir o SEP como uma de suas referências; que o SEP atenda aos padrões mínimos requeridos pelo SUS e/ou SUAS, principalmente, observando o princípio da equidade e a diretriz da regionalização.

O lugar que os SEP ocupam atualmente impossibilita o atendimento, por exemplo, ao princípio da integralidade e aos pressupostos da humanização e interdisciplinaridade inerentes à política nacional de saúde. Tampouco, permite práticas que tenham como foco a garantia e o restabelecimento de direitos, em articulações intersetoriais, relativos ao SUAS. Dessa forma, os estagiários pouco ou quase nada vivenciam em termos da complexidade dos sistemas das políticas públicas, dificultando o exercício profissional a partir de uma atuação em rede.

\section{Contribuição dos Serviços Escola para a Formação de Acordo com Estagiários}

A maioria das falas dos estagiários e egressos credita ao SEP importância central para sua formação. A "visão clínica"; as "competências psicoterápicas"; a "escuta que é muito singular no espaço da clínica"; "o manejo, a transferência/contratransferência e implicação" e "o aprendizado clínico" são referências à psicologia que podem limitar as competências e habilidades para a atuação nas políticas de saúde 
e assistência social. Nessa perspectiva, os SEP têm formado para a atuação do psicólogo na área clínica, o que, possivelmente, pode ser um dos motivos por que no Brasil "a clínica é a área de atuação predominante para o psicólogo, ela está se estendendo para além dos consultórios particulares e penetrando em instituições públicas de saúde e no terceiro setor" (Gondim et al., 2010, p. 197).

Entretanto, algumas falas dos estagiários participantes da pesquisa ressaltam a importância do SEP no sentido de proporcionar a realização de atividades em articulação com equipamentos das redes de saúde e assistência social. Esse cenário pode representar um avanço, comparado ao modelo predominante de SEP apenas como clínica escola. Em geral, os estagiários e egressos apontam que as atividades e o modo de funcionamento dos SEP atendem às suas expectativas. Justificaram sua satisfação afirmando que o SEP proporciona a "relação teoria $e$ prática", "trazer à realidade", bem como aprimora "o que foi aprendido em sala de aula", "preparando para o futuro profissional", para a prática clínica, atendendo "às necessidades dos estagiários e da clientela", "despertando autonomia e a responsabilidade", atendendo pessoas de baixa renda e por ter o "respaldo de pessoas experientes". Essas referências revelam uma compreensão da importância da prática para o exercício profissional.

Outras falas indicam a "possibilidade de realizar psicoterapia com postura crítica"; "aberto para a clínica ampliada, apesar de predominar a clínica tradicional"; "possibilita conhecer a clínica"; permite "o contato com diferentes campos de atuação do psicólogo e diferentes serviços". Oportuniza "práticas em diversos contextos"; "formação ética e com cuidado com o humano"; propicia o desenvolvimento de "atividades que a teoria preparou"; a realização de "reuniões de equipe" e desenvolver "competências e acolher dúvidas".

No que se refere aos aspectos administrativos, foram evidenciados pelos estagiários "problemas com marcação de salas"; "com erros nas fichas"; sobrecarga para o estagiário por parte dos técnicos de nível superior ou tutores dos
SEP; "comunicação deficiente entre estagiários e profissionais". Ainda, a fraca articulação interinstitucional e o fato de que os "funcionários poderiam ser mais bem capacitados, bem como ter maior variedade de atividades", foram aspectos indicados como insatisfatórios. Além disso, o tempo "curto" de estágio; a "falta de sala específica para a realização de avaliação psicológica"; a pouca articulação entre os Serviços Escola e a rede de saúde e a defasagem na área de Psicologia do Trabalho, na "consultoria empresarial e em projetos de orientação profissional" foram outros aspectos mal avaliados pelos participantes em relação aos Serviços Escola.

A avaliação dos SEP por parte dos estagiários e egressos remete, portanto, à possibilidade do exercício prático dos conhecimentos aprendidos em sala de aula, bem como à qualidade dos supervisores e à boa estrutura física do serviço. Esses resultados podem proporcionar a reflexão, por parte dos gestores e do corpo técnico das instituições formadoras, sobre a necessidade da incorporação formal de estratégias de ensino nos SEP que priorizem: (a) o desenvolvimento de habilidades e competências para atuação nas políticas públicas (Yamamoto, 2003); (b) atividades voltadas para a garantia e restabelecimento dos sistemas de direitos (Alberto, Freire, Leite, \& Gouveia, 2014); (c) práticas que garantam a manutenção dos cuidados em saúde nas dimensões longitudinal e transversal (Dimenstein, 2014); e (d) em parceria com os serviços públicos de saúde (Spink, Brigadão, \& Nascimento, 2014).

Uma postura crítica começa a ser desenvolvida nos estagiários, quando apontam lacunas nesses estabelecimentos, os quais deixam "a desejar", conforme o relato a seguir de estagiário(a):

Deixa a desejar na clínica e social; prioriza a clínica, o atendimento individual, estando longe das outras unidades de saúde da comunidade, sem troca de experiências, sem compartilhamento de casos, enfim, creio que a clínica deveria estar mais em contato com os demais serviços de saúde. (SEP 4 ES37)

Desse modo, as atividades nos SEP, sua participação no processo de formação, ainda neces- 
sitam de um investimento para a preparação dos estagiários para atuação nas políticas públicas, apesar de serem percebidos alguns movimentos nessa direção. Trata-se de repensar a formação para atuação profissional a partir de uma concepção do papel e compromisso social do psicólogo e de suas práticas, dando lugar a um projeto de formação interdisciplinar e em consonância com as políticas públicas.

\section{Considerações Finais}

Os quatro SEP pesquisados possuem características híbridas nas quais coexiste o modelo de Clínica Escola, focado em práticas institucionais e psicológicas tradicionais, tais como a psicoterapia individual, a avaliação e triagem e as novas modalidades de ação, de prestação de serviços à comunidade, envolvendo diferentes atores, instituições e redes, em particular, de saúde e assistência social. Apesar de serem ainda pouco articuladas e incipientes, já indicam uma preocupação com a formulação de novas premissas para a atuação do psicólogo sintonizadas com um saber-fazer crítico sobre a própria formação e as possibilidades de intervenção na realidade onde se insere. Entretanto, como mencionado anteriormente, a característica preponderante é a atuação de forma isolada de outras instâncias acadêmicas e profissionais, com ausência de práticas interdisciplinares e ferramentas técnicas para atuar no âmbito das políticas públicas em coerência com as demandas sociais e políticas da sociedade brasileira. Nesse sentido, constatamos uma relação informal e frágil entre os Serviços Escola e as redes de assistência social e de saúde, cuja prática predominante é a do encaminhamento de mão dupla, sem estabelecimentos de parcerias efetivas, sustentadas pela corresponsabilização e continuidade de cuidados.

O crescimento no quantitativo dos cursos de psicologia no país pode se configurar como uma preocupação a mais com as práticas dos Serviços Escola, principalmente se consideramos a afirmação de Mello e Patto (2008) sobre as instituições de ensino "que não passam de empresas que vendem cursos de Psicologia de olho no lucro, sem atenção à responsabilidade presente na ou- torga de diplomas a profissionais treinados para dizer arbitrariedades e absurdos como se estivessem dizendo verdades inquestionáveis" (p. 593).

Em que pesem as rápidas mudanças na sociedade, as transformações na formação acadêmica não têm acompanhado seu ritmo e a realidade dos cursos pesquisados não é diferente da realidade nacional. Acompanhando a análise de Abbad e Mourão (2010), consideramos que novas competências para a inserção do psicólogo nas políticas de assistência social e de saúde ainda não vêm sendo desenvolvidas de modo satisfatório nos cursos de psicologia. Estamos diante do predomínio da formação tradicional focada no trabalho isolado e individual, com defasagem de competências para o trabalho em equipe e com populações vulneráveis socialmente.

Notamos a escassez de práticas integrativas, na oferta de atividades grupais, de visitas e atendimentos domiciliares, orientação familiar, práticas de proteção de direitos, de fortalecimento e empoderamento comunitário, enfim, de alternativas que extrapolem o lugar comum ocupado pela psicologia. Essa perspectiva tem sido reforçada pelo modo de funcionamento dos Serviços Escola locais, que têm estado pouco permeáveis à incorporação de novos princípios de trabalho e diretrizes de ação que inaugurem outro lugar social para os espaços de formação acadêmico-profissional, tal como vem sendo proposto nas experiências que articulam ensino-serviço-comunidade, com a utilização de diversas estratégias didático-pedagógicas. Segundo Medeiros, Fidelis, Pinto e Nuto (2011), "a articulação ensino-serviço-comunidade, estratégia para a efetivação da integração teoria-prática, é, então, alcançada pela inserção precoce dos alunos em cenários reais e diversificados de ensino-aprendizagem" (p. 29).

Tais experiências vêm alargando o conhecimento das necessidades e problemas de saúde da população em seus territórios, revelando a necessidade de capacitação dos docentes em novas metodologias de ensino, bem como de aproximação de professores e estudantes com as redes de saúde, assistência social e comunidades. Resta, então, uma indagação: até que ponto estamos dispostos a fazer dos Serviços Escola cenários 
de problematização do lugar social ocupado pelo psicólogo, de reflexão e intervenção nas condições de existência, de produção de sujeitos que insistem em se indignar e lutar por uma psicologia que rompa com as tendências higienistas, excludentes, preconceituosas e tecnicistas que ainda caracterizam nosso campo de saber e práticas?

Assim, concordamos com Yamamoto (2012), quando aponta que, "em vez de qualificar as ações profissionais como socialmente comprometidas ou não, poderíamos pensar nelas vinculadas ou articuladas a um ou a outro projeto ético-político profissional" (p. 14). Trata-se de um projeto no qual a formação não seja completamente isolada daquela dos demais profissionais que atuam nas políticas públicas, especialmente, do campo da seguridade social. Portanto, vale repensar o SEP integrado - não apenas em termos de espaço, mas em suas práticas - a outros cursos e estes, por sua vez, às redes do sistema de seguridade social.

Finalizando, observamos que, no geral, os SEP do RN ainda não estão acompanhando as Diretrizes Curriculares Nacionais, no que concerne à ampliação da formação para a atuação do psicólogo em variados contextos. Ademais, ainda continuam focando suas atividades na formação do profissional liberal, estando distantes das políticas públicas. Será que os cursos de psicologia das IES do RN estão limitados a esperar pela oferta de vagas para estágio nos equipamentos públicos de assistência social e de saúde? Com a ampliação de vagas e o aumento na quantidade de cursos de psicologia, já não seria a hora de os SEP se inserirem nas redes dessas políticas sociais?

\section{Referências}

Abbad, G. S., \& Mourão, L. (2010). Competências profissionais e estratégias de qualificação e requalificação. In A. V. B. Bastos \& S. M. G. Gondim (Eds.), O trabalho do psicólogo no Brasil (pp. 380-401). Porto Alegre, RS: Artmed.

Alberto, M. F. P., Freire, M. L., Leite, F. M., \& Gouveia, C. N. N. A. (2014). As políticas públicas de assistência social e atuação profissional. In
I. F. Oliveira \& O. H. Yamamoto (Eds.), Psicologia e politicas sociais: Temas em debate (pp. 127-174). Belém, PA: Editora da Universidade Federal do Pará.

Bardagi, M. P., Bizarro, L., Andrade, A. M. J., Audibert, A., \& Lassanc, M. C. P. (2008). Avaliação da formação e trajetória profissional na perspectiva de egressos de um curso de psicologia. Psicologia: Ciência e Profissão, 28(2), 304-315. doi:10.1590/S1414-98932008000200007

Bastos, A. V. B., \& Gomide, P. I. (1989). O psicólogo brasileiro: Sua atuação e formação profissional. Psicologia: Ciência e Profissão, 9(1), 6-15. doi:10.1590/S1414-98931989000100003

Bastos, A. V. B., \& Gondim, S. M. G. (Eds.). (2010). O trabalho do psicólogo no Brasil. Porto Alegre, RS: Artmed.

Bernardes, J. S. (2007). A psicologia no SUS 2006: Alguns desafios na formação. In M. J. P. Spink (Ed.), A psicologia em diálogo com o SUS: Prática profissional e produção acadêmica (pp. 105-127). São Paulo, SP: Casa do Psicólogo.

Bernardes, J. S. (2010). A psicologia no SUS 2006: Alguns desafios na formação. In M. J. P. Spink (Ed.), A psicologia em diálogo com o SUS: Prática profissional e produção acadêmica (2. reimpressão rev., pp. 105-127). São Paulo, SP: Casa do Psicólogo.

Bernardes, J. S., \& Menegon, V. S. M. (2007). Documentos de domínio público como produtos e autores sociais. Psico, 38(1), 11-15.

Boeckel, M. G., Krug, J. S., Lahm, C. R., Ritter, F., Fontoura, L. O., \& Sohne, L. C. (2010). O papel do serviço-escola na consolidação do projeto pedagógico do curso de Psicologia. Psicologia: Ensino \& Formação, 1(1), 41-51.

Ceccim, R. B., \& Feuerwerker, L. C. M. (2004). O quadrilátero da formação para a área da saúde: Ensino, gestão, atenção e controle social. Physis: Revista de Saúde Coletiva, 14(1), 41-65.

Conselho Federal de Psicologia. (Ed.). (1988). Quem é o psicólogo brasileiro? São Paulo, SP: Edicon.

Conselho Federal de Psicologia. (Ed.). (1992). Psicólogo brasileiro: Construção de novos espaços. Campinas, SP: Átomo.

Conselho Federal de Psicologia. (Ed.). (1994). Psicólogo brasileiro: Práticas emergentes e desafios para a formação. São Paulo, SP: Casa do Psicólogo. 
Conselho Nacional de Educação, Câmara de Educação Superior (2004). Resolução $n$. 8, de 7 de maio de 2004. Recuperado em http://webcache.googleusercontent.com/ search?q=cache:http://portal.mec.gov.br/ cne/arquivos/pdf/rces 08 _04.pdf\&gws $\mathrm{rd}=$ cr\&ei $=$ Z5qoV8RWhKPCBPDPhsgD

Dimenstein, M. (1998). O psicólogo nas unidades básicas de saúde: Desafios para a formação e atuação profissionais. Estudos de Psicologia (Natal), 3(1), 53-81. doi:10.1590/S1413$-294 X 1998000100004$

Dimenstein, M. (2000). A cultura profissional do psicólogo e o ideário individualista: Implicações para a prática no campo da assistência pública à saúde. Estudos de Psicologia (Natal), 5(1), 95 121. doi:10.1590/S1413-294X2000000100006

Dimenstein, M. (2014). A psicologia no campo da saúde mental. In I. F. de Oliveira \& O. H. Yamamoto (Eds.), Psicologia e políticas sociais: Temas em debate. Belém, PA: Editora da Universidade Federal do Pará.

Dimenstein, M., \& Macedo, J. P. (2010). Desafios para o fortalecimento da psicologia no SUS: A produção referente à formação e inserção profissional. In M. J. P. Spink (Ed.), A psicologia em diálogo com o SUS: Prática profissional e produção acadêmica (2. reimpressão rev., pp. 207-234). São Paulo, SP: Casa do Psicólogo.

Dimenstein, M., \& Macedo, J. P. (2012). Formação em Psicologia: Requisitos para atuação na atenção primária e psicossocial [Número especial]. Psicologia: Ciência e Profissão, 32, 232-245. doi:10.1590/S1414-98932012000500017

Gondim, S. M. G., Bastos, A. V., \& Peixoto, L. S. A. (2010). Áreas de atuação, atividades e abordagens teóricas do psicólogo brasileiro. In A. V. B. Bastos \& S. M. G. Gondim (Eds.), O trabalho do psicólogo no Brasil (pp. 174-199). Porto Alegre, RS: Artmed.

Lei n. 4.119, de 27 de agosto de 1962. (1962, 17 dez.). Dispõe sôbre os cursos de formação em psicologia e regulamenta a profissão de psicólogo. Diário Oficial da União. Recuperado em http:// www.planalto.gov.br/ ccivil_03/leis/1950-1969/ L4119.htm

Lo Bianco, A. C., Bastos, A. V. B., Nunes, M. L. T., \& Silva, R. C. (1994). Concepções e atividades emergentes na psicologia clínica: Implicações para a formação. In Conselho Federal de Psicologia (Ed.), Psicólogo brasileiro: Práticas emer- gentes e desafios para a formação (pp. 7-76). São Paulo, SP: Casa do Psicólogo.

Macedo, J. P. S., \& Dimenstein, M. (2011). Formação do psicólogo para a saúde mental: A psicologia piauiense em análise. Interface - Comunicação, Saúde, Educação, 15(39), 1145-1157. doi:10.1590/S1414-32832011005000021

Malvezzi, S. (2010). A profissionalização dos psicólogos: Uma história de promoção humana. In A. V. B. Bastos \& S. M. G. Gondim (Eds.), O trabalho do psicólogo no Brasil (pp. 17-31). Porto Alegre, RS: Artmed

Marturano, E. M., Silvares, E. F. de M., \& Oliveira, M. da S. (2014). Serviços-escola de psicologia: Seu lugar no circuito de permuta do conhecimento. Temas em Psicologia, 22(2), 457-470. doi:10.9788/TP2014.2-15

Maturana, H. (2005). Emoções e linguagem na educação e na política. Belo Horizonte, MG: Universidade Federal de Minas Gerais.

Medeiros, M. A. S., Fidelis, G. M. A., Pinto, W. M., \& Nuto, S. de A. S. (2011, dez.). Integração Ensino-Serviço e Atenção Farmacêutica. Caderno FNEPAS, 1 .

Mello, S. L. de, \& Patto, M. H. S. (2008). Psicologia da violência ou violência da psicologia? Psicologia USP, 19(4), 591-594. doi:10.1590/S010365642008000400013

Melo-Silva, L. L., Santos, M. A., \& Simon, C. P. (2005). Serviço-Escola em Psicologia: A construção do saber prático. In L. L. Melo-Silva, M. A. Santos, \& C. P. Simon, Formação em Psicologia - Serviços-escola em debate (pp. 21-30). São Paulo, SP: Vetor.

Mendes, N. M. (n.d.). Histórico da Psicologia no RN e a organização da categoria no Conselho de Psicologia. In Conselho Regional de Psicologia da $17^{\mathrm{a}}$ Região - Rio Grande do Norte, Histórico. Recuperado em http://www.crprn.org.br/institucional/historico/

Menicucci, T. M. G. (2002). Intersetorialidade: O desafio atual para as políticas sociais. Pensar $\mathrm{BH}$. Política Social, 3, 0-13.

Ministério da Educação. (2011). Resolução n. 5, de 15 de março de 2011. Recuperado em http:// portal.mec.gov.br/index.php?option $=$ com docman\&view $=$ download\&alias $=7692$ rces005-11-pdf\&category_slug=marco-2011pdf\&Itemid $=30192$ 
Noronha, A. P. (2003). Docentes de psicologia: Formação profissional. Estudos de Psicologia (Natal), 8(1), 169-173. doi:10.1590/S1413$-294 X 2003000100019$

Nunes, M. L. T., Campezatto, P. V. M., Cruxên, O. S., \& Savalhia, J. A. D. (2006). Clínicas-escola de psicologia e psicoterapia psicanalítica: $\mathrm{O}$ duplo desafio de atender com qualidade à clientela e propiciar ao acadêmico uma boa formação. In B. Werlang \& M. Oliveira (Eds.), Temas em psicologia clínica (pp. 36-45). São Paulo, SP: Casa do Psicólogo.

Oliveira, I. F., Solon, A. F. A. C., Amorim, K. M. O., \& Dantas, C. M. B. (2011). A prática psicológica na proteção social básica do SUAS [Número especial]. Psicologia \& Sociedade, 23, 140-149. doi:10.1590/S0102-71822011000400017

Oliveira, M. S., Pereira, R. F., Peixoto, A. C. A., Rocha, M. M., Oliveira-Monteiro, N. R., Macedo, M. M. K., \& Silvares, E. F. M. (2014). Supervisão em serviços-escola de psicologia no Brasil: Perspectiva dos supervisores e estagiários. Psico, 45(2), e1-e9. doi:10.15448/19808623.2014.2.15417

Paulin, T., \& Luzio, C. A. (2009). A Psicologia na Saúde Pública: Desafios para a atuação e formação profissional. Revista de Psicologia da UNESP, 8(2).

Pazeto, A. E. (2005). Universidade, formação e mundo do trabalho: Superando a visão corporativa. Ensaio: Avaliação e Políticas Públicas em Educação, 13(49), 487-496. doi:10.1590/S010440362005000400006

Romaro, R. A., \& Capitão, C. G. (2003). Caracterização da clientela da clínica-escola de Psicologia da Universidade São Francisco. Psicologia: Teoria e Prática, 5(1), 111-121.

Silvares, E. F. M. (1996). É satisfatório o atendimento psicológico nas clínicas escolas brasileiras? In R. M. L. Carvalho (Ed.), Coletâneas da ANPEPP: Vol. 9. Repensando a formação do psicólogo: Da informação à descoberta (pp. 137-145). Campinas, SP: Alínea.

Silvares, E. F. M. (Ed). (2006). Atendimento psicológico em clínicas-escola. Campinas, SP: Alínea.

Silvares, E. F. M. (Coord.). (2008). O atendimento psicológico nas clínicas-escola: Convergências atuais (2008-2009). In J. Q. Pinheiro \& F. S. Albuquerque (Eds.), Anais do XII Simpósio de Pesquisa e Intercâmbio Científico da ANPEPP: Conhecimento em Psicologia no Brasil:
Expansão e avaliação. Recuperado em http:// www.anpepp.org.br/old/XIISimposio/XII-GTs/ GT_30_AtendPsicologicoClinicasEscola.pdf

Spink, M. J. P. (2003). Psicologia social e saúde: Práticas, saberes e sentidos. Petrópolis, RJ: Vozes.

Spink, M. J. P., Brigadão, J. I. M., \& Nascimento, V. L. V. (2014). Psicólogos(as) no SUS: A convivência necessária com as políticas de saúde. In I. F. Oliveira \& O. H. Yamamoto (Eds.), Psicologia e políticas sociais: Temas em debate (pp. 9-243). Belém, PA: Editora da Universidade Federal do Pará.

Yamamoto, O. H. (2001). Espaços, práticas: O que há de novo na psicologia no Rio Grande do Norte? Psicologia em Estudo, 6(2). doi:10.1590/S141373722001000200009

Yamamoto, O. H. (2003). Questão social e políticas públicas: Revendo o compromisso da psicologia. In A. M. B. Bock (Ed.), Psicologia e o compromisso social (pp. 37-53). São Paulo, SP: Cortez.

Yamamoto, O. H. (2007). Políticas sociais, "terceiro setor" e "compromisso social": Perspectivas e limites do trabalho do psicólogo. Psicologia \& Sociedade, 19(1), 30-37. doi:10.1590/S010271822007000100005

Yamamoto, O. H. (2012). 50 anos de profissão: Responsabilidade social ou projeto ético-político [Número especial]? Psicologia: $\mathrm{Ci}$ ência e Profissão, 32. doi:10.1590/S141498932012000500002

Yamamoto, O. H., Dantas, C. M. B., Costa, A. L. F., Alverga, A. R., Seixas, P. S., \& Oliveira, I. F. (2003). A profissão de psicólogo no Rio Grande do Norte. Interação, 7(2), 23-30.

Yamamoto, O. H., \& Oliveira, I. F. (2011). Política Social e Psicologia: Uma trajetória de 25 anos [Número especial]. Psicologia: Teoria e Pesquisa, 26. doi:10.1590/S0102-37722010000500002

Yamamoto, O. H., Siqueira, G. S., \& Oliveira, S. C. C. (1997). A Psicologia no Rio Grande do Norte: Caracterização geral da formação acadêmica e do exercício profissional. Estudos em Psicologia (Natal), 2(1), 42-66. 